\title{
Estimating the Impact of Delayed Access to Oncology Drugs on Patient Outcomes in Canada
}

\author{
Jackie Vanderpuye-Orgle · Daniel Erim • Yi Qian · Devon J. Boyne • \\ Winson Y. Cheung • Gwyn Bebb • Ariel Shah • Louisa Pericleous • \\ Maciej Maruszczak · Darren R. Brenner
}

Received: December 8, 2021 / Accepted: January 21, 2022 / Published online: March 1, 2022

(C) The Author(s) 2022

\begin{abstract}
Introduction: New requirements in Canada's pricing processes for patented drugs may exacerbate delays in regulatory and reimbursement reviews. This study seeks to better understand the impact of any additional delays on nonsmall cell lung cancer (NSCLC) patients by measuring the following: (a) durations and
\end{abstract}

Supplementary Information The online version contains supplementary material available at https:// doi.org/10.1007/s40487-022-00187-3.

This work was presented as a poster at Virtual ISPOR Europe 2020, 16-19 November 2020.

J. Vanderpuye-Orgle $(\bowtie) \cdot$ D. Erim Advanced Analytics, HEOR and RWE, Parexel International, Billerica, MA, USA

e-mail: Jackie.Vanderpuye-Orgle@parexel.com

Y. Qian · G. Bebb · A. Shah

Amgen Inc, Thousand Oaks, CA, USA

D. J. Boyne · W. Y. Cheung · G. Bebb · D. R. Brenner Department of Oncology, University of Calgary, Calgary, AB, Canada

D. J. Boyne - W. Y. Cheung - D. R. Brenner Oncology Outcomes (O2) Initiative, University of Calgary, Calgary, AB, Canada

L. Pericleous

Amgen Canada Inc, Mississauga, ON, Canada

M. Maruszczak

Advanced Analytics, HEOR and RWE, Parexel International, London, UK outcomes of regulatory and reimbursement reviews of NSCLC drugs in Canada and reference countries; (b) delays in Canada's reviews of three NSCLC drugs (nivolumab, afatinib, and pemetrexed [NAP]); and (c) estimating clinical, patient, and economic impacts of delays in Canada's reviews on access to NAP.

Methods: Information from the Context Matters database and the literature (2005-2020) was used to evaluate the durations and outcomes of reimbursement reviews of NSCLC drugs in Canada and comparator countries. Public information was used to assess delays in Canada's reviews of NAP. Empirical modeling with data from the literature and the Southern Alberta Lung Cancer database was used to estimate the impact of delays in Canada's NAP reviews on patients (i.e., as losses in personyears of life and quality-adjusted life-years [QALYs]).

Results: Regulatory and reimbursement reviews in countries of interest take 12-18 months. In Canada, reviews of NSCLC drugs took 216 days (median), with a $24 \%$ rejection rate $($ mean $=19 \%)$. Delays in NAP reviews ranged from 5 to 94 days at Health Canada, 0-80 days at CADTH/pCODR, and 12-797 days in Canadian provinces. These delays may have affected 6400 patients, who lost up to 1740 person-years of life and 1122 QALYs (valued at CA $\$ 112$ million).

Conclusion: Changes to Canada's prescription drug pricing processes may prolong reviews. 
Keywords: NSCLC; Targeted therapies; HTA; CADTH; Reimbursement; Canada; Patient access; QALY; Quality of life

\section{Key Summary Points}

The implementation of the Patented Medicine Prices Review Board new pricing regulations in Canada, now planned for July 2022, may potentially impact the review process for new therapies and delay patient access to new drugs.

We reviewed the durations of regulatory and reimbursement reviews of three novel therapies for non-small cell lung cancer (nivolumab, afatinib and pemetrexed).

We predict that the planned changes may delay patient access to new drug treatments with potential impacts on patient quality of life and survival.

\section{INTRODUCTION}

Canada spends $1.74 \%$ of its gross domestic product (GDP) on prescription drugs [1]; however, Canadians with public drug coverage continue to have restricted or delayed access to new therapies ${ }^{1}[2,3]$. These delays are due to the many-layered sequential review processes that inform public drug plans' decisions on whether to provide access to new medicines [2, 4]. Rawson (2014) and Gotfrit et al. (2020) [2] have described how delays in Canadian regulatory and reimbursement approvals adversely affect cancer patients' survival [2, 5]. Delays may be exacerbated by the recent reforms by the Canadian regulator of patented drug prices (i.e., the Patented Medicine Prices Review Board [PMPRB]) to review processes to address pharmaceutical spending [1, 6-8]. For context,

\footnotetext{
$\overline{1}$ Not every patient diagnosed will be subject to delay, as more than $60 \%$ of Canadians have private drug coverage and may not be affected by the timing of provincial drug program decisions.
}

patients' access to oncology drugs in Canada requires submissions to Health Canada (for Notice of Compliance [NOC] with all relevant safety laws), the Canadian Agency for Drugs and Technologies in Health/pan-Canadian Oncologic Drug Review (CADTH-pCODR) and/or Institut National d'Excellence en Santé et en Services Sociaux (INESSS [Québec only]), and to provincial authorities to ultimately decide if and when to initiate reimbursement $[4,9]$. Afterwards, the PMPRB sets a price ceiling, while provincial authorities (through the pan-Canadian Pharmaceutical Alliance [pCPA]) may further negotiate lower drug prices with manufacturers $[8,10,11]$. Benchmarks used in price setting include prices of other drugs in the same therapeutic class in Canada, changes to Canada's consumer price indices, and prices of the indicated drug in reference countries (i.e., France, Germany, Italy, Sweden, the United Kingdom, Switzerland, and the United States of America) [11-13]. Reforms to pricing review processes planned to be implemented from January 2022 (and since delayed to July 2022) will require new drug submissions to include information that describes a drug's estimated pharmacoeconomic value, anticipated market size, and GDP/GDP per capita of reference countries $[6,14]$. Additionally, the list of reference countries will be reconstituted to include only developed countries that typically have lower patented drug prices than Canada (i.e., Switzerland and the United States will be removed, while Australia, Belgium, Japan, the Netherlands, Norway, and Spain will be added). These new requirements will likely increase the complexity of new drug submissions [15], potentially lengthening the durations of pricing reviews and delaying reimbursement decisions [7]. These changes may also delay access to innovative cancer medicines, and little is known about how cancer patients are likely to be affected.

To better understand the potential consequences of proposed pricing reforms for cancer patients, this study had two overarching goals: to compare the durations and outcomes of regulatory and reimbursement reviews of oncology drugs in Canada and PMPRB's new reference countries, and to gain insight into 
population-level impacts of delayed access to lung cancer drugs. Lung cancer is the number one cause of cancer-related death in Canada, so it was selected as our focus for this study [16]. Current clinical practice guidelines recommend testing for biomarkers, often termed "must-test genes," including epidermal growth factor receptor (EGFR), BRAF, ROS1, and programmeddeath ligand-1 (PD-L1), prior to treatment initiation, as these have been shown to predict response to therapy, guide treatment decisions, and affect outcomes [17-19]. Several techniques are available for these biomarker tests, which are dependent on several factors, including sample size and type, institution protocols, and cost [20]. The selected lung cancer drugs represent three different therapy classes-one immunotherapy drug (nivolumab), one broadindication targeted inhibitor (afatinib), and one broad-indication chemotherapy drug (pemetrexed)-collectively referred to hereinafter as NAP (we chose one analogue to represent each class in our analysis of patient- and populationlevel impacts).

\section{METHODS}

\section{Overview}

This study involves several components: analyses of data on durations and outcomes of health technology assessment (HTA) reviews of nonsmall cell lung cancer (NSCLC) drugs in Canada and reference countries (2005-2020); targeted literature reviews of pathways to pharmaceutical market access in countries of interest; analyses of data on the durations of regulatory and reimbursement reviews of NAP in Canada; and empirical modeling with data from the literature and patient-level information from a retrospective analysis of real-world data.

\section{Compliance with Ethics Guidelines}

This article is based on previously conducted studies and does not contain any new studies with human participants or animals performed by any of the authors. The deidentified patient information used in this retrospective observational study does not include any identifiable information, and an institutional review board (IRB) approval or waiver is therefore not required.

\section{Data}

\section{Regulatory and HTA Reviews of Oncology Drugs in Canada and Reference Countries}

An analytic dataset was created using abstracted information from the Clarivate ${ }^{\mathrm{TM}}$ Market Access Platform database (formerly Context Matters). The database contains drug-specific data on clinical trials and HTA reviews/determinations for various countries and uses machine learning to capture, structure, and standardize disparate data sets. For this analysis, reference countries included Australia, the Netherlands, Spain, France, Germany, Italy, Sweden, and England (all of which are PMPRB current or proposed comparator countries), and abstracted information included generic/brand names, manufacturer, indication, and dates and outcomes of HTA reviews (between 2005 and 2020). Oncology drugs of interest were for NSCLC due to the high unmet need and speed of innovation. Targeted literature reviews were used to supplement abstracted information and to examine pathways/steps involved in regulatory and HTA review processes for new drug applications in reference countries.

\section{Public Records of Canadian Regulatory and HTA Review of NAP}

Data on Canadian regulatory reviews of NAP were abstracted from the following sources: the Summary Basis of Decision Post-Authorization Activity and the Regulatory Decision Summary Tables for reviews at Health Canada (e.g., submission dates, NOC dates, and priority/standard review status) [21]; CADTH-pCODR Review Summary Details and INESSS's website for HTA reviews (e.g., pre-/post-NOC review status, submission dates, priority/standard review status, initial recommendation dates, and final recommendation dates) [22]; and CADTH-pCODR Provincial Funding Summary files for 
information on provincial reimbursements for NAP [23].

\section{Southern Alberta Lung Cancer Database}

This is a large, real-world, institutional database that captures demographic, tumor, laboratory, treatment, and outcome information for individuals diagnosed with lung cancer in Southern Alberta, Canada [24, 25]. The database has 2 million individuals in its catchment area, and data collection involves extracting information from patients' medical records, tumor registry data, pathology reports, pharmacy records, and treatment summaries. Data used for analyses came from patients who received a lung cancer diagnosis between 2010 and 2016 (i.e., when NSCLC data collection started to obtain mature overall survival data).

\section{Analyses}

\section{Benchmarking HTA Reviews on NSCLC Drugs in Canada and Reference Countries}

Abstracted information from the Context Matters database was used to determine the durations and outcomes of HTA reviews of NSCLC drug submissions to the indicated agencies. The durations of HTA reviews were summarized by HTA agency and year, while time trends (median durations) by year and HTA agency were assessed using Pearson's correlation coefficients. Outcomes of HTA reviews included recommend for reimbursement without restrictions (or recommend), recommend for reimbursement with restrictions (or recommend with restrictions), do not recommend for reimbursement (i.e., reject), and unknown. Rates of rejection were also summarized by HTA agency.

\section{Quantifying Delays in Canada's Regulatory and HTA Review of NAP}

The durations of regulatory and reimbursement review of NAP were compared to review timelines internally established by Health Canada and CADTH/pCODR. Delays were defined as the number of days used in reviewing NAP above and beyond indicated benchmarks (i.e., D1 and D2 for delays at Health Canada and CADTHpCODR, respectively [see Supplementary Fig. 1,
Panels A and B]). INESSS does not provide internal performance benchmarks, and delays related to the INESSS HTA review process were not quantified. As performed in a previous study, delays in provincial reimbursement were defined relative to the first provincial reimbursement for NAP (D3 for delays at Canadian provinces [see Supplementary Fig. 1, Panels A and B]) [26].

\section{Impacts of Delays in Canada's Regulatory and Reimbursement Reviews of NAP}

The concept of delay is best understood by visualizing the process of clinical decision making on cancer treatment at points of care. A 1-day delay in the review of a new drug could make it unavailable to some patients with approved indications; the associated opportunity costs may be captured as lower health-related quality of life and/or overall survival if the new drug is safer and/or more effective than the current standard of care. For example, Gotfrit et al. [2] state that the literature "demonstrates that for 21 drugs effective in advanced malignancies, 1 life-year is lost worldwide for every 12 -s delay from the time of drug discovery to approval" [2].

In our analyses, the Southern Alberta Lung Cancer database was used to estimate the proportion of newly diagnosed NSCLC patients with appropriate indications for NAP as well as their overall survival (see Supplementary Table 1 for more details).

Numbers of NSCLC patients affected by delays were calculated as the product of three estimates: new NSCLC cases diagnosed per day in Canada/each Canadian province (from Canadian Cancer Statistics); proportion of NSCLC cases with appropriate indications for NAP (see Supplementary Figs. 1, 2, and 3 for more details); and length of delay (days) in regulatory and reimbursement reviews of NAP (i.e., D1, D2, or D3).

The person-years of life lost (PYLL) to delays were calculated as follows: (1) relative increases in the median overall survival of NSCLC patients due to NAP were estimated by dividing the median overall survival in the investigational arm by the median overall survival in the comparator arm from CheckMate-057 (for 
nivolumab), LUX-Lung 7 (for afatinib), and PARAMOUNT (for pemetrexed) trials (see Supplementary Table 2 for more details); (2) the median survival of NSCLC patients in the real world with appropriate indications for NAP was estimated from the Southern Alberta Lung Cancer database; (3) the hypothetical survival of individuals in the real world had they received NAP was estimated as the product of 1 and 2 (i.e., the relative increase in median overall survival in the randomized control trial [RCT] times the observed median overall survival in the real world); (4) the PYLL per patient was calculated as the difference between the value estimated in steps 3 and 2 (i.e., the hypothetical median overall survival of patients in the real world had they received NAP minus the observed median overall survival); and (5) the PYLL per patient estimated in step (4) was multiplied by the number of patients affected by delays in regulatory and/or reimbursement reviews of NAP [26-31].

Quality-adjusted life-years (QALYs) lost to delays were estimated as the product of PYLL to indicated delays and weighted utilities associated with use of NAP in NSCLC patients (across all lines of therapy and disease progression states [i.e., 0.63 for nivolumab and pemetrexed and 0.66 for afatinib]) [32, 33]. Lastly, economic values of QALYs lost to delays in regulatory and reimbursement reviews of NAP were estimated by valuing each lost QALY at CA $\$ 100,000$ [34, 35]. In sensitivity analyses, alternative specifications for patients with appropriate NAP indications $( \pm 20 \%)$, utilities $( \pm 20 \%)$, and progressive declines in delays at Health Canada, CADTH-pCODR, and provincial authorities (by $50 \%$ and $100 \%$ ) were assessed.

\section{RESULTS}

\section{Pathways, Durations, and Outcomes of Reviews on Oncology Drugs in Canada and Reference Countries}

The expected durations of regulatory and HTA reviews on oncology drugs in Canada and other countries of interest are presented in Fig. 1 $[21,22,36-55]$. Overall, the data suggest that most countries take $12-18$ months to complete reviews on new submissions for oncology drugs. The shortest and longest HTA review durations were reported for Germany (approximately 210 days) and Spain (up to 735 days), respectively. Additionally, several countries have multiple agencies in their regulatory and access review pathways, and each require sequential (or rarely, concurrent) review steps. For example, Australian regulatory and HTA reviews of new oncology drugs are performed by two agencies, the Therapeutic Goods Administration (TGA) and the Pharmaceutical Benefits Advisory Committee (PBAC), and reviews may last up to 2 years [40]. Canada also has an intricate review process involving several agencies (i.e., Health Canada, CADTH-pCODR, pCPA, and provincial authorities, some with undisclosed review steps) and reviews new drug applications with a target of 18 months for Health Canada and CADTH combined, but not including the subsequent pCPA and provincial processes.

The durations and outcomes of regulatory and/or HTA reviews of new applications for NSCLC drugs in Canada and reference countries are presented in Table 1. We found 416 eligible records of new drug applications submitted to relevant regulatory and HTA agencies between 2009 and 2020. The rejection rate for NCSLC drugs ranged from $0 \%$ (e.g., Italy and Sweden) to $35 \%$ (Australia) and was $24 \%$ in Canada (median and mean rejection rates for NSCLC drugs were $19 \%$ and $19 \%$, respectively). The median durations of review ranged from 182 to 1053 days (216 days in Canada). Lastly, we found no evidence of significant time trends in median durations of regulatory and HTA reviews of NSCLC drugs in Canada or reference countries.

\section{Canadian Regulatory and Reimbursement Reviews of NAP}

When reviewing new drug applications, Health Canada sets a target of 205 days for priority reviews and 345 days for standard reviews, while CADTH-pCODR sets a target of 180 days for HTA reviews. Details of reviews of NAP by 


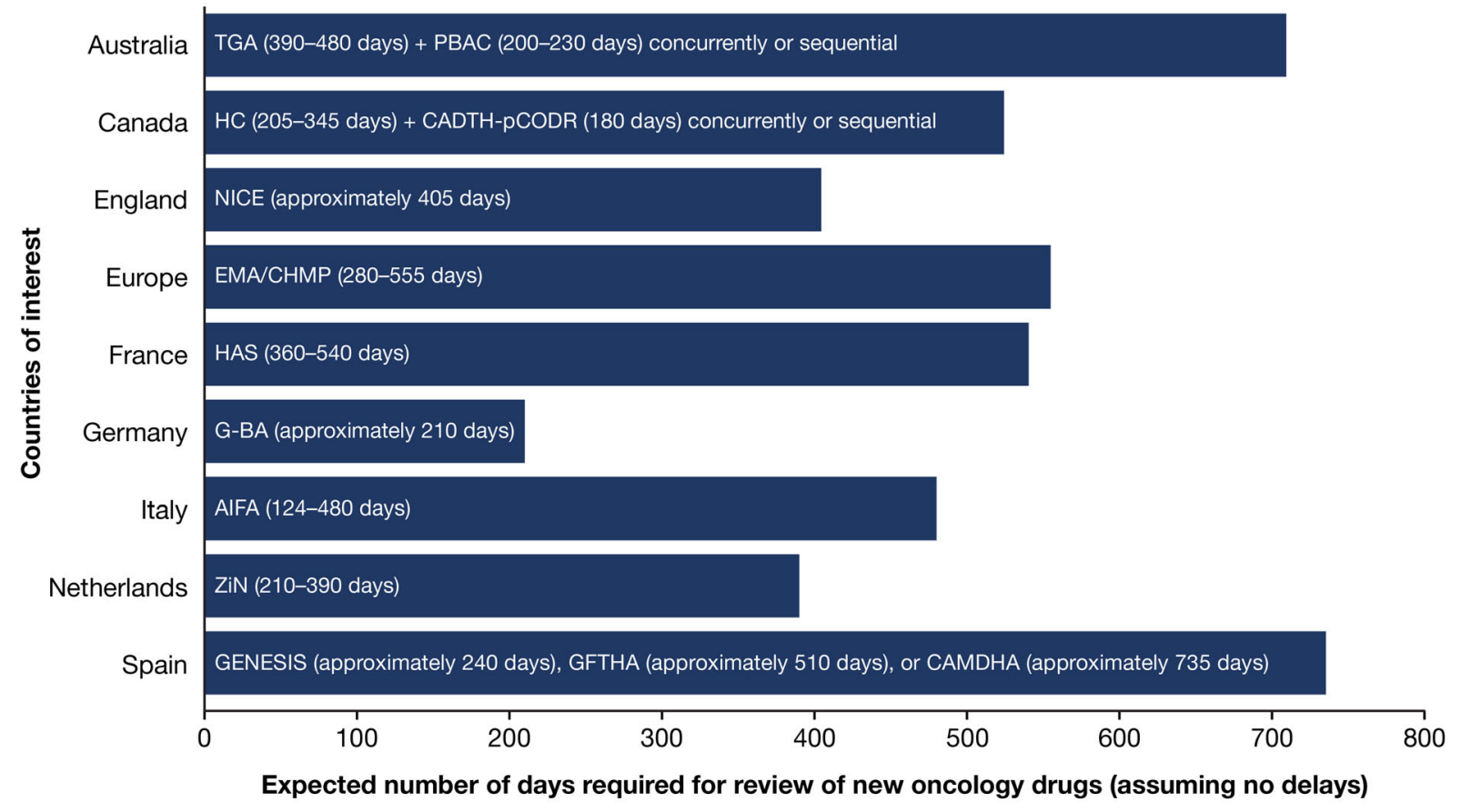

Fig. 1 Expected durations of regulatory and HTA reviews of oncology drugs in Canada and some reference countries. Estimated durations assume no regulatory delays. TGA, Therapeutic Goods Administration [36-38]; PBAC, Pharmaceutical Benefits Advisory Committee [39, 40]; HC, Health Canada [21]; CADTH, Canadian Agency for Drugs and Technologies in Health [22]; pCODR, panCanadian Oncology Drug Review [22], INESSS, Institut National d'Excellence en Santé et en Services Sociaux [41]; NICE, National Institute for Health and Care Excellence [42]; EMA/CHMP, European Medicines Agency/Committee for Medicinal Products for Human Use [43-45];

Health Canada, CADTH-pCODR, and provincial authorities are presented in Table 2. Health Canada completed a priority review of nivolumab in 210 days (i.e., D1 delay for nivolumab was 5 days) and a standard review of afatinib in 439 days (i.e., D1 delay for afatinib was 94 days from agency-set targets). Nivolumab and afatinib submissions to CADTH-pCODR were preNOC; thus, indicated D1 delays at Health Canada were subsumed within D2 delays at CADTH-pCODR, as they did not impact commencement of HTA reviews. Information on the submission date for pemetrexed was unavailable. CADTH-pCODR completed priority HTA review of nivolumab in 148 days and standard
HAS, Haute Autorité de Santé [46-48]; G-BA, Gemeinsamer Bundesausschuss [49]; AIFA, Agenzia Italiana del Farmaco [50, 51]; ZiN, Zorginstituut Nederland [52, 53]; CAMHDA, Advisory Board of Hospital Medication Dispensed to Outpatients [54, 55]; GENESIS, Group for Innovation, Assessment, Standardization and Research in the Selection of Drugs [54, 55]; and GFTHA, Andalusian Hospital Formulary guideline [54, 55]. Market access in Germany and the Netherlands may also be attained via the centralized EMA/CHMP pathway. HTA health technology assessment

HTA review of pemetrexed in 140 days (i.e., no D2 delays for nivolumab and pemetrexed). However, CADTH-pCODR completed standard HTA review on afatinib in 260 days (i.e., D2 delay for afatinib was 80 days from agency-set targets). Delays in provincial reviews of NAP ranged between 12 days (Manitoba) and 518 days (Prince Edward Island) for nivolumab, between 23 days (New Brunswick) and 797 days (Prince Edward Island) for afatinib, and between 29 days (Ontario, Nova Scotia, and Newfoundland and Labrador) and 630 days (Prince Edward Island) for pemetrexed. 
Table 1 Durations and outcomes of new applications for NSCLC drugs to HTA agencies of interest

\begin{tabular}{llll}
\hline Country & \multicolumn{2}{l}{ Non-small cell lung cancer } \\
\cline { 2 - 4 } & Reports & Rejection rates & Median duration of review (days) \\
\hline Australia & 65 & $35 \%$ & 214 \\
Canada & 29 & $24 \%$ & 216 \\
England & 57 & $32 \%$ & - \\
France & 82 & $11 \%$ & 739 \\
Germany & 74 & $0 \%$ & 182 \\
Italy & 7 & $0 \%$ & - \\
Netherlands & 3 & $33 \%$ & - \\
Spain & 28 & $14 \%$ & 1053 \\
Sweden & 11 & $0 \%$ & -
\end{tabular}

HTA agencies included in our review (by country) include the following: Australia - PBAC (Pharmaceutical Benefits Advisory Committee); Canada - CADTH (Canadian Agency for Drugs and Technologies in Health), CCO (Cancer Care Ontario), and pCODR (pan-Canadian Oncology Drug Review); England - NICE (National Institute for Health and Care Excellence); France - HAS (Haute Autorité de Santé); Germany-G-BA (Gemeinsamer Bundesausschuss); Italy-AIFA (Agenzia Italiana del Farmaco); Netherlands - ZiN (Zorginstituut Nederland); Spain - CAMHDA (Advisory Board of Hospital Medication Dispensed to Outpatients), CatSalut (Departament de Salut de la Generalitat de Catalunya), CFTA de Illes Balears (Comissió Farmacoterapèutica Autonòmica de Illes Balears), GENESIS-SEFH (Group for Innovation, Assessment, Standardisation and Research in the Selection of Drugs-a division of the Spanish Society of Hospital Pharmacy), GFTHA (Andalusian Hospital Formulary guideline), HGU Gregorio Marañón (Hospital General Universitario Gregorio Marañón), HU de Guadalajara (Hospital Universitario de Guadalajara), HU Virgen del Rocío (Hospital Universitario Virgen del Rocio), HUPR (Hospital Universitario de La Princesa), and ICO (Institut Català d'Oncologia); Sweden - TLV (Tandvårds- och läkemedelsförmånsverket)

$H T A$ health technology assessment, NSCLC non-small cell lung cancer

\section{Impacts of Delays in Access to NAP on Canadian NSCLC Patients}

Estimated access and economic impacts of delays in access to NAP are summarized in Table 3. More than 6400 Canadian NSCLC patients were affected by delays in regulatory and reimbursement reviews of NAP, which varied between 51 patients in Saskatchewan and 4177 in Québec. All assessed delays were calculated to result in the loss of 1740 person-years of life and 1122 QALYs valued at over CA $\$ 112$ million. Further details are presented in Supplementary Tables 3, 4, and 5. Results of the sensitivity analyses are presented in Table 4 . Study findings were largely robust to alternative specifications of utilities and patients with appropriate indications for NAP. The results also indicated that the benefits of reduced provincial delays were significantly larger than the benefits of reduced delays at CADTH-pCODR (see Table 4 for further details).

\section{DISCUSSION}

Study findings suggest that delays currently exist in the Canadian regulatory and reimbursement review process for oncology drugs, and these delays may impact the lives of cancer patients and, by extension, the Canadian economy. These findings highlight several noteworthy implications, some of which apply to upcoming reforms in setting price ceilings for patented drugs in Canada. It is also worth 
Table 2 Regulatory and HTA submission and decision dates, as well as delays in regulatory review of nivolumab, afatinib, and pemetrexed

\begin{tabular}{|c|c|c|c|}
\hline & Nivolumab & Afatinib & Pemetrexed \\
\hline \multicolumn{4}{|l|}{ Health Canada } \\
\hline Date of initial submission & July 31,2015 & August 19, 2012 & Unavailable \\
\hline Review type & Priority & Standard & Standard \\
\hline NOC date & February 26, 2016 & November 1, 2013 & May 9, 2013 \\
\hline Duration of review (days) & 210 & 439 & - \\
\hline Internal benchmark (days) & 205 & 345 & - \\
\hline Delay (days) & 5 & 94 & - \\
\hline \multicolumn{4}{|l|}{ CADTH-pCODR } \\
\hline Date of initial submission & October 29, 2015 & June 7, 2013 & May 31, 2013 \\
\hline $\begin{array}{l}\text { Date submission deemed } \\
\text { complete }\end{array}$ & November 5, 2015 & June 19, 2013 & June 13, 2013 \\
\hline Pre-NOC submission & Yes & Yes & No \\
\hline Review type & Priority & Standard & Standard \\
\hline $\begin{array}{l}\text { Date of initial } \\
\text { recommendation }\end{array}$ & April 1, 2016 & March 6, 2014 & October 31, 2013 \\
\hline Final recommendation date & June 20, 2016 & May 20, 2014 & December 4, 2013 \\
\hline Duration of review (days) & 148 & 260 & 140 \\
\hline Internal benchmark (days) & 180 & 180 & 180 \\
\hline Delay (days) & 0 & 80 & 0 \\
\hline \multicolumn{4}{|c|}{ Provincial reimbursements (dates and delays $[$ days $]$ ) } \\
\hline British Columbia & $\begin{array}{l}\text { March 1, } 2017 \text { (First to } \\
\text { approve) }\end{array}$ & October 1,2014 ( 43 days) & May 1, 2014 (59 days) \\
\hline Manitoba & March 13, 2017 (12 days) & October 16, 2014 (58 days) & June 1,2014 (90 days) \\
\hline Québec & March 15, 2017 (14 days) & May 4, 2016 (624 days) & October 1,2014 (212 days) \\
\hline Ontario & March 21, 2017 (20 days) & $\begin{array}{l}\text { August 19, } 2014 \text { (First to } \\
\text { approve) }\end{array}$ & April 1, 2014 (29 days) \\
\hline Saskatchewan & March 23, 2017 (22 days) & $\begin{array}{l}\text { September 15, } 2014 \\
\text { (27 days) }\end{array}$ & $\begin{array}{l}\text { March 3, } 2014 \text { (First to } \\
\text { approve) }\end{array}$ \\
\hline Nova Scotia & April 1, 2017 (31 days) & $\begin{array}{l}\text { December 29, } 2014 \\
\quad(132 \text { days })\end{array}$ & April 1, 2014 (29 days) \\
\hline Alberta & April 3, 2017 (33 days) & $\begin{array}{l}\text { September 30, } 2014 \\
\text { (42 days) }\end{array}$ & May 1, 2014 (59 days) \\
\hline New Brunswick & May 2, 2017 (62 days) & $\begin{array}{l}\text { September } 11,2014 \\
\text { (23 days) }\end{array}$ & $\begin{array}{l}\text { September } 1,2014 \\
\text { (182 days) }\end{array}$ \\
\hline
\end{tabular}


Table 2 continued

\begin{tabular}{llll}
\hline & Nivolumab & Afatinib & Pemetrexed \\
\hline Newfoundland and Labrador & August 3, 2017 (155 days) & June 1, 2015 (286 days) & April 1, 2014 (29 days) \\
Prince Edward Island & August 1, 2018 (518 days) & October 24, 2016 (797 days) & $\begin{array}{c}\text { November 23, 2015 } \\
\text { (630 days) }\end{array}$ \\
\hline
\end{tabular}

Data on the durations of reviews at INESSS were unavailable. Nivolumab and afatinib submissions to CADTH-pCODR were made pre-NOC; thus, delays within the Health Canada review process would not impact the start of the HTA review and would be captured by the delay within the HTA review process. There is a lack of data on the initial submission of pemetrexed

CADTH Canadian Agency for Drugs and Technologies in Health, NOC Notice of Compliance, $p C O D R$ pan-Canadian Oncology Drug Review

Table 3 Estimated impacts of a 1-day delay in access to nivolumab, afatinib, and pemetrexed at national and provincial levels

\begin{tabular}{lllll}
\hline Canadian provinces & $\begin{array}{l}\text { Number of patients } \\
\text { affected }\end{array}$ & $\begin{array}{l}\text { Person-years of life } \\
\text { lost }\end{array}$ & $\begin{array}{l}\text { Lost } \\
\text { QALYs }\end{array}$ & $\begin{array}{l}\text { Economic value of lost } \\
\text { QALYs }\end{array}$ \\
\hline Alberta & 292 & 82 & 52 & CA\$5.2 M \\
British Columbia & 388 & 108 & 69 & CA\$6.9 M \\
Manitoba & 149 & 43 & 27 & CA\$2.7 M \\
New Brunswick & 184 & 58 & 37 & CA\$3.7 M \\
Newfoundland and & 133 & 33 & 22 & CA\$2.2 M \\
$\quad$ Labrador & 148 & 37 & 24 & CA\$2.4 M \\
Nova Scotia & 706 & 192 & 124 & CA\$12.4 M \\
Ontario & 178 & 52 & 33 & CA\$3.3 M \\
Prince Edward Island & 4177 & 1123 & 725 & CA\$72.5 M \\
Québec & 51 & 12 & 8 & CA\$0.8 M \\
Saskatchewan & $\mathbf{6 4 0 6}$ & $\mathbf{1 7 4 0}$ & $\mathbf{1 1 2 2}$ & CA\$112.2 M \\
All provinces & &
\end{tabular}

QALYs quality-adjusted life years (valued at CA\$100,000/QALY), M million

noting that the way the current comparator basket is constructed, prices in other comparator countries would be inevitably lower than Canadian prices, revealing an inherent bias in the selection of this basket, possibly designed to buttress the authorities' bargaining power. It is also worth looking at whether average prices in the newly selected countries are above or below the Organisation for Economic Co-operation and Development (OECD) average. Using this measure, out of the six new countries, only Australia and the Netherlands have prices below the OECD average. 
Table 4 Results of sensitivity analyses

\begin{tabular}{|c|c|c|c|c|}
\hline Scenarios & Patients affected & PYLL lost & QALYs lost & Value of lost QALYs \\
\hline Lower utilities (by $20 \%$ ) & 6406 & 1740 & 897 & CA $\$ 89.7 \mathrm{M}$ \\
\hline Higher utilities (by 20\%) & 6406 & 1740 & 1346 & CA $\$ 134.6 \mathrm{M}$ \\
\hline Fewer eligible patients (by $20 \%$ ) & 5124 & 1392 & 897 & CA $\$ 89.7 \mathrm{M}$ \\
\hline More eligible patients (by 20\%) & 7683 & 2087 & 1345 & $\mathrm{CA} \$ 134.5 \mathrm{M}$ \\
\hline Reduced CADTH-pCODR delays (by $50 \%$ ) & 5961 & 1638 & 1055 & CA $\$ 105.5 \mathrm{M}$ \\
\hline Reduced CADTH-pCODR delays (by 100\%) & 5517 & 1536 & 988 & CA $\$ 98.8 \mathrm{M}$ \\
\hline Reduced provincial delays (by $50 \%$ ) & 3647 & 972 & 628 & $\mathrm{CA} \$ 62.8 \mathrm{M}$ \\
\hline Reduced provincial delays (by 100\%) & 889 & 203 & 134 & $\mathrm{CA} \$ 13.4 \mathrm{M}$ \\
\hline
\end{tabular}

QALYs were valued at CA $\$ 100 \mathrm{~K} / \mathrm{QALY}$

CADTH-pCODR Canadian Association of Drugs and Technologies in Health/pan-Canadian Oncologic Drug Review, $M$ million, $P Y L L$ person-years of life lost, QALYs quality-adjusted life years

Upcoming pricing reforms in Canada's drug review processes (implementation from July 2022) may delay manufacturer submissions for new drugs (e.g., altering preparatory materials/ procedures to meet new submission or review requirements) and/or lead to higher rejection rates for new applications (e.g., partial responsiveness to new submission and/or review requirements). In the justification for the delays in implementation of the new pricing regulations, Health Canada has recognized the time needed by stakeholders to adapt to the new requirements and the impact of the COVID-19 pandemic $[6,56]$. There is precedent from 2014 when the Scottish Medicines Consortium reformed their prescription drug evaluation processes and ended up with higher rejection rates for new oncology submissions [57]. Study findings indicate that Canada already has moderate to high rejection rates for innovative cancer medicines relative to reference countries, which may disincentivize new drug applications [56, 58]. Indeed this is supported by emerging evidence indicating that there has already been a significant drop in the number of applications to Health Canada since PMPRB guidelines have been under review, suggesting that manufacturers may be delaying or declining to submit new drug applications [59]. This trend may delay access to innovative cancer drugs (see Table 3).

There are other potential sources of delay after the introduction of the proposed PMPRB reforms. For example, use of pharmacoeconomic evaluations may introduce delays in the following contexts: when there are dissimilar analytic perspectives across HTA agencies (e.g., health system vs. societal perspectives at CADTH-pCODR and INESSS, respectively) and when there is a need to delay final decisions until after all relevant evaluations are complete and available, i.e., usually 1-2 years after product launches in Canada [60, 61]. Additionally, the changes to the basket of price reference countries may incentivize manufacturers to defer product launch in Canada until product prices have stabilized in reference countries or if the allowable price in Canada will have a cost impact internationally $[58,60]$. These and other reform-attributable consequences may inadvertently add to delays that already exist in the Canadian regulatory and reimbursement review systems, further exacerbating adverse patientand population-level outcomes as demonstrated in this study.

We have demonstrated in this study that delays in regulatory and reimbursement reviews of NAP may have affected over 6400 NSCLC patients and may have led to the loss of more 
than 1700 person-years of life and 1100 QALYs, and that lung cancer patients represent $13 \%$ of all new cancer cases in Canada [62]. Hence, further delays in patients gaining access to new cancer drugs would not only affect more patients but would also proportionally increase the number of person-years of life and QALYs lost to delays. At the individual level, these delays take away the opportunity for Canadian cancer patients to live longer and make additional contributions to society. At the macro level, the opportunity cost includes significant productivity losses. In post hoc analyses using the World Health Organization (WHO)CHOICE approach (2020 costs, using Choosing Interventions that are Cost-Effective), we determined that the productivity loss associated with delays in regulatory and reimbursement reviews of NAP was at least CA $\$ 106$ million. This is likely to be an underestimate as it does not include productivity loss from NSCLC-attributable disability [63]. This estimate of productivity loss is different from the economic value of lost QALYs (i.e., CA $\$ 112$ million), which represents the amount Canadian authorities should be willing to spend to eliminate every delay encountered during reimbursement reviews on NAP.

This study has several strengths. First, we were able to estimate the proportion of patients with an appropriate indication for the treatment of interest using a large, real-world Canadian database [5]. Second, we were also able to estimate median survival using the Southern Alberta Real-World Database rather than relying on estimates from respective clinical trials (overestimates PYLL) [5]. Third, our perspective on delays was comprehensive and accounted for the entire regulatory review pathway.

This study also has some limitations. The empirical analyses rely on several assumptions, many of which are difficult to test. For example, these analyses assume that patients on current therapies will not switch to a new treatment when it becomes available, that $100 \%$ of eligible patients would also be willing to receive the new treatment of interest, that the levels of adherence are comparable between the clinical trials and real-world settings, and that the incidence of lung cancer is constant throughout the year. We were unable to quantify the burden due to delayed access attributable to the HTA review process within Québec-one of the largest provinces in Canada-due to a lack of availability in submission dates. Hence, our estimates will likely underestimate the burden of delayed access attributable to HTA review delay in Canada. In estimating the number of NSCLC cases affected by delays in reviews of NAP, we assumed that demographic and clinical characteristics of Alberta residents were similar to those in other Canadian provinces [64].

In general, drugs perform better in premarket clinical trials than they do when used in the real world. Survival data from single studies, such as the PARAMOUNT RCT, are useful but are not as representative as real-world evidence from systematic reviews and retrospective data analyses. This can be construed as another limitation.

With respect to the QALYs lost, we were unable to estimate treatment-specific health state utility values representative of the general Canadian cancer population. As a result, the QALYs lost due to delayed access do not account for differences between treatments that are due to the quality of life-instead, they are based exclusively on differences between treatments due to the length of life. As such, the QALYs should be interpreted as the QALYs lost due to early mortality attributable to delayed access to the select oncologic therapies. If the new therapies are related to improved quality of life while on therapy, this approach will lead to an underestimation of the total QALYs lost due to delayed access to cancer drugs. Additionally, we did not explicitly account for pCPA processing delays, which have been reported as a significant contributor to delays in reimbursement reviews [4].

The patient population included in the model is large and heterogeneous in terms of histology and biomarker status (PD-L1 expression levels, EGFR mutation positivity, etc.) [26-31]. The data presented in the current study did not factor these into the analyses, which may have impacted the results in terms of overall survival $[65,66]$ and, potentially, the calculation of PYLL and QALYs. Future research may be needed to determine whether these 
results are robust when we explicitly account for patient heterogeneity and potential differences in treatment response. These limitations may affect the accuracy of our estimates.

\section{CONCLUSION}

Current delays in Canada's regulatory and reimbursement reviews of NAP for lung cancer patients were calculated to be associated with losses of over 1700 person-years of life, 1100 QALYs, and CA $\$ 106$ million (productivity losses). Anticipated pricing reforms may increase pre-existing delays and exacerbate adverse outcomes for Canadian NSCLC patients and their contribution to the economy.

\section{ACKNOWLEDGEMENTS}

Funding. Amgen Inc. funded this work and the journal's Rapid Service Fee.

Medical Writing and Editorial Assistance. Editorial and medical writing support was provided by Sue Neville, MSc, of Parexel and funded by Amgen.

Authorship. All named authors meet the International Committee of Medical Journal Editors (ICMJE) criteria for authorship for this article, take responsibility for the integrity of the work as a whole, and have given their approval for this version to be published.

Author contributions. Jackie VanderpuyeOrgle, Daniel Erim, and Maciej Maruszczak drafted the manuscript. All authors contributed to the analysis, and reviewed and revised the draft manuscript.

Prior presentation. This work was presented as a poster at Virtual ISPOR Europe 2020, 16-19 November 2020.

Disclosures. Jackie Vanderpuye-Orgle PhD, MSc is employed by Parexel International. Daniel Erim MD, PhD, MSc, was employed by
Parexel International at the time the work was undertaken and is now employed by Janssen Scientific Affairs LLC. Maciej Maruszczak, MSc was employed by Parexel International at the time the work was undertaken and is now employed by MAP Biopharma Ltd.

Yi Qian PhD was employed by Amgen Inc at the time the work was undertaken and is now employed by Janssen. Ariel Shah, MBA is employed by Amgen Inc. Louisa Pericleous, $\mathrm{PhD}$, is employed by Amgen Canada Inc. Devon J Boyne PhD, Winson Y. Cheung MD, MPH, and Darren R Brenner PhD are consultants to Amgen Inc. At the time of the study, Gwyn Bebb, BMBCh, PhD, was a consultant to Amgen Inc and he is now employed by Amgen Inc.

Compliance with Ethics Guidelines. This article is based on previously conducted studies and does not contain any new studies with human participants or animals performed by any of the authors. The deidentified patient information used in this retrospective observational study does not include any identifiable information, and an institutional review board (IRB) approval or waiver is therefore not required.

Data Availability. All data generated or analyzed during this study are included in this published article/as supplementary information files.

Open Access. This article is licensed under a Creative Commons Attribution-NonCommercial 4.0 International License, which permits any non-commercial use, sharing, adaptation, distribution and reproduction in any medium or format, as long as you give appropriate credit to the original author(s) and the source, provide a link to the Creative Commons licence, and indicate if changes were made. The images or other third party material in this article are included in the article's Creative Commons licence, unless indicated otherwise in a credit line to the material. If material is not included in the article's Creative Commons licence and your intended use is not permitted by statutory regulation or exceeds the permitted use, you will need to obtain permission directly from the 
copyright holder. To view a copy of this licence, visit http://creativecommons.org/licenses/by$\mathrm{nc} / 4.0 /$.

\section{REFERENCES}

1. Organisation for Economic Co-operation and Development. Pharmaceutical spending. 2021. https://data.oecd.org/healthres/pharmaceuticalspending.htm. Accessed 10 Aug 2021.

2. Gotfrit J, Shin JJW, Mallick R, Stewart DJ, WheatleyPrice P. Potential life-years lost: the impact of the cancer drug regulatory and funding process in Canada. Oncologist. 2020;25(1):e130-7.

3. Millson B, Thiele S, Zhang Y, Dobson-Belaire W, Skinner B. Access to new medicines in public drug plans: Canada and comparable countries. 2016 annual report. 2016. http://innovativemedicines. ca/wp-content/uploads/2016/05/20160524_Access_ to_Medicines_Report_EN_Web.pdf. Accessed 10 Aug 2021.

4. Salek S, Lussier Hoskyn S, Johns JR, Allen N, Sehgal C. Factors influencing delays in patient access to new medicines in Canada: a retrospective study of reimbursement processes in public drug plans. Front Pharmacol. 2019;10(196). https://doi.org/10. 3389/fphar.2019.00196.

5. Rawson NSB. Has pCODR improved access to oncology drugs? Timeliness and provincial acceptance of pan-Canadian Oncology Drug Review recommendations. 2014. https://www.fraserinstitute. org/sites/default/files/has-pCODR-improved-accessto-oncology-drugs-rev.pdf. Accessed 12 Aug 2021.

6. Guerreiro CA, Daley BR, Wall K. PMPRB update: delayed implementation of patented medicines regulations amendments and new guidelines. 2021. https://www.pharmainbrief.com/2021/07/pmprbupdate-delayed-implementation-of-patentedmedicines-regulations-amendments-and-newguidelines/. Accessed 10 Aug 2021.

7. Rawson NSB. New review rules-the impact on drug access in Canada. 2021. https://www.fraserinstitute. org/blogs/new-review-rules-the-impact-on-drugaccess-in-canada. Accessed 12 Aug 2021.

8. Canada ponders a federal programme for pharmaceuticals. Economist. 2020. https://econ.st/ 35nMuiV. Accessed 10 Sept 2020.

9. Canadian Agency for Drugs and Technologies in Health. Health Canada, CADTH, and INESSS collaborate to align drug review processes. https:// bit.ly/3iirUUW. Accessed 10 Sept 2020.

10. Canadian Association of Provincial Cancer Agencies. The Pan-Canadian Cancer Drug Funding Sustainability Initiative. https://bit.ly/35jjLMm. Accessed 10 Sept 2020.

11. Oakes K. Canada's drug price reforms delayed to 2021. Regulatory Focus. 2020. https://bit.ly/ 3mbQGbx. Accessed 10 Sept 2020.

12. Patented Medicine Prices Review Board. 2020. http://pmprb-cepmb.gc.ca/home. Accessed 10 Aug 2021.

13. Canadian Agency for Drugs and Technologies in Health. The path forward for integrating key functions of the Cancer Drug Implementation Advisory Committee (CDIAC) into CADTH's pan-Canadian Oncology Drug Review (pCODR) process. https:// cadth.ca/news/path-forward-integrating-keyfunctions-cancer-drug-implementation-advisorycommittee-cdiac. Accessed 18 Mar 2020.

14. Government of Canada. PMPRB guidelines. 2021. https://www.canada.ca/en/patented-medicineprices-review/services/legislation/about-guidelines/ guidelines.html. Accessed 9 Feb 2022.

15. Humphries B, Xie F. Canada's amendment to patented drug price regulation: a prescription for global drug cost control? JAMA. 2019;321(16): 1565-6.

16. Sung H, Ferlay J, Siegel RL, et al. Global cancer statistics 2020: GLOBOCAN estimates of incidence and mortality worldwide for 36 cancers in 185 countries. CA Cancer J Clin. 2021;71(3):209-49.

17. Ettinger DS, Wood DE, Aisner DL, et al. NCCN Guidelines insights: non-small cell lung cancer, version 2.2021. J Natl Compr Canc Netw. $2021 ; 19(3): 254-66$.

18. Melosky B, Banerji S, Blais N, et al. Canadian consensus: a new systemic treatment algorithm for advanced EGFR-mutated non-small-cell lung cancer. Curr Oncol. 2020;27(2):e146-55.

19. Mosele F, Remon J, Mateo J, et al. Recommendations for the use of next-generation sequencing (NGS) for patients with metastatic cancers: a report from the ESMO Precision Medicine Working Group. Ann Oncol. 2020;31(11):1491-505.

20. Pisapia P, Pepe F, Baggi A, et al. Next generation diagnostic algorithm in non-small cell lung cancer predictive molecular pathology: The KWAY Italian multicenter cost evaluation study. Crit Rev Oncol Hematol. 2021;169:103525. 
21. Health Canada. The Drug and Health Product Register. https://hpr-rps.hres.ca/index.php. Accessed 5 Dec 2019.

22. Canadian Agency for Drugs and Technologies in Health. Find a Review (pCODR). https://www. cadth.ca/pcodr/find-a-review. Accessed 4 Dec 2019.

23. Institut national d'excellence en santé et services sociaux. Drug products undergoing evaluation and evaluated. https://www.inesss.qc.ca/index.php?id= 42\&L=1\&DemandePluginController\%5BEVALUES_ pointer $\% 5 \mathrm{D}=6 \&$ DemandePluginController $\%$ 5Bonglet $\% 5 \mathrm{D}=1 \& \mathrm{cHash}=$ Obbdc773b160e477934dde85e2881a8f. Accessed 10 Dec 2019.

24. Gibson AJW, Li H, D'Silva A, et al. Factors associated with early mortality in non-small cell lung cancer patients following systemic anti-cancer therapy: a 10 year population-based study. Lung Cancer. 2019;134:141-6.

25. Gibson AJW, Li H, D'Silva A, et al. Comparison of clinical characteristics and outcomes in relapsed versus de novo metastatic non-small cell lung cancer. Am J Clin Oncol. 2019;42(1):75-81.

26. Paz-Ares L, de Marinis F, Dediu M, et al. Maintenance therapy with pemetrexed plus best supportive care versus placebo plus best supportive care after induction therapy with pemetrexed plus cisplatin for advanced non-squamous non-small-cell lung cancer (PARAMOUNT): a double-blind, phase 3 , randomised controlled trial. Lancet Oncol. 2012;13(3):247-55.

27. Horn L, Spigel DR, Vokes EE, et al. Nivolumab versus docetaxel in previously treated patients with advanced non-small-cell lung cancer: two-year outcomes from two randomized, open-label, phase III trials (CheckMate 017 and CheckMate 057). J Clin Oncol. 2017;35(35):3924-33.

28. Vokes EE, Ready N, Felip E, et al. Nivolumab versus docetaxel in previously treated advanced nonsmall-cell lung cancer (CheckMate 017 and CheckMate 057): 3-year update and outcomes in patients with liver metastases. Ann Oncol. 2018;29(4): 959-65.

29. Paz-Ares L, Tan E-H, O'Byrne K, et al. Afatinib versus gefitinib in patients with EGFR mutation-positive advanced non-small-cell lung cancer: overall survival data from the phase IIb LUX-Lung 7 trial. Ann Oncol. 2017;28(2):270-7.

30. Yang JC-H, Wu Y-L, Schuler M, et al. Afatinib versus cisplatin-based chemotherapy for EGFR mutationpositive lung adenocarcinoma (LUX-Lung 3 and LUX-Lung 6): analysis of overall survival data from two randomised, phase 3 trials. Lancet Oncol. 2015;16(2):141-51.

31. Canadian Agency for Drugs and Technologies in Health. Afatinib (Giotrif) advanced NSCLC - pERC final recommendation. 2014. https://www.cadth. $\mathrm{ca} /$ sites/default/files/pcodr/pcodr-giotrif-nsclc-fnrec.pdf. Accessed 20 Dec 2021.

32. Paracha N, Abdulla A, MacGilchrist KS. Systematic review of health state utility values in metastatic non-small cell lung cancer with a focus on previously treated patients. Health Qual Life Outcomes. 2018;16(1):179.

33. Chouaid C, Agulnik J, Goker E, et al. Health-related quality of life and utility in patients with advanced non-small-cell lung cancer: a prospective cross-sectional patient survey in a real-world setting. J Thorac Oncol. 2013;8(8):997-1003.

34. Laupacis A, Feeny D, Detsky AS, Tugwell PX. How attractive does a new technology have to be to warrant adoption and utilization? Tentative guidelines for using clinical and economic evaluations. CMAJ. 1992;146(4):473.

35. Working Group to Inform the Patented Medicine Prices Review Board (PMPRB) Steering Committee on Modernization of Price Review Process Guidelines. Final report. 2019. http://www.pmprbcepmb.gc.ca/CMFiles/Consultations/new guidelines/final-report-en.pdf. Accessed 31 Aug 2020 .

36. Australian Government Department of Health, Therapeutic Goods Administration. Prescription medicines registration process. 2021. https://www. tga.gov.au/prescription-medicines-registrationprocess. Accessed 9 Feb 2022.

37. Australian Government Department of Health, Therapeutic Goods Administration. Fast track approval pathways. https://www.tga.gov.au/fasttrack-approval-pathways. Accessed 10 Sept 2020.

38. APEC Harmonization Center. Drug Approval System of Australia. 2016. https://www.nifds.go.kr/ brd/m_95/down.do?brd_id=board_mfds_411\&seq= $23200 \&$ data_tp=A\&file_seq $=2$. Accessed $10 \mathrm{Sept}$ 2020.

39. Australian Government Department of Health. Listing process. The Pharmaceutical Benefits Scheme. https://www.pbs.gov.au/pbs/industry/ listing/procedure-guidance/2-listing-process/ listing-process. Accessed 10 Sept 2020.

40. Parliament of Australia, Community Affairs Reference Committee. Availability of new, innovative and specialist cancer drugs in Australia. 2015. https://www.aph.gov.au/Parliamentary_Business/ 
Committees/Senate/Community_Affairs/Cancer_ Drugs/Report. Accessed 12 Aug 2021.

41. Institut national d'excellence en santé et en services sociaux (INESSS). Evaluation process and criteria. https://www.inesss.qc.ca/en/themes/medicaments/ evaluation-process-and-criteria.html. Accessed 7 Oct 2020.

42. National Institute for Health and Care Excellence. https://www.nice.org.uk/. Accessed 10 Sept 2020.

43. European Medicines Agency. The evaluation of medicines, step-by-step. 2020. https://www.ema. europa.eu/en/human-regulatory/marketingauthorisation/evaluation-medicines-stepstep\#final-discussion-and-adoption-of-opinionsection. Accessed 10 Sept 2020.

44. Medicines Evaluation Board. Centralised procedure. https://english.cbg-meb.nl/topics/mah-centralisedprocedure. Accessed 10 Sept 2020.

45. Federal Institute for Drugs and Medical Devices. Centralized licensing procedures. https://www. bfarm.de/EN/Drugs/licensing/zulassungsverfahren/ cp/_node.html. Accessed 10 Sept 2020.

46. Robert C, Long GV, Brady B, et al. Nivolumab in previously untreated melanoma without BRAF mutation. N Engl J Med. 2015;372(4):320-30.

47. Haute Autorité de Santé. Summary of the Transparency Committee opinion - Keytruda (pembrolizumab), anti-PD1 antibody. 2017. https:// www.has-sante.fr/upload/docs/application/pdf/ 2018-12/keytruda_melanome_sapub_ct15825_en_ def.pdf. Accessed 10 Sept 2020.

48. Haute Autorité de Santé. Brief summary of the HAS Board opinion. OPDIVO (nivolumab), anti-PD-1 antibody. 2016. https://www.has-sante.fr/upload/ docs/application/pdf/2016-10/opdivomelanome_ summary_ct14578.pdf. Accessed 10 Sept 2020.

49. Federal Institute for Drugs and Medical Devices. Decentralised procedure (DCP)/mutual recognition procedure (MRP). https://www.bfarm.de/EN/Drugs/ licensing/zulassungsverfahren/dcp_mrp/_node. html. Accessed 10 Sept 2020.

50. Russo P, Mennini F, Siviero P, Rasi G. Time to market and patient access to new oncology products in Italy: a multistep pathway from European context to regional health care providers. Ann Oncol. 2010;21(10):2081-7.

51. Lanati E, Lidonnici D, Ronco V. Italian timings in new drugs approval: an up-to-date analysis. Value Health. 2016;19(7):A448.
52. Medicines Evaluation Board. Decentralised procedure. https://english.cbg-meb.nl/topics/mah-decentral ised-procedure. Accessed 10 Sept 2020.

53. Medicines Evaluation Board. Marketing authorisation medicines for human use. https://english.cbgmeb.nl/sections/marketing-authorisationmedicines-for-human-use. Accessed 10 Sept 2020.

54. Lozano-Blázquez A, Dickson R, Fraga-Fuentes M-D, Martínez-Martínez F, Calleja-Hernández M-Á. Differences in cancer drug assessment between Spain and the United Kingdom. Eur J Cancer. 2015;51(13):1843-52.

55. Emergo by UL. AEMPS - Spanish Agency of Medicine and Sanitary Products. https://www. emergobyul.com/resources/europe/spain-agencymedicine-sanitary-products. Accessed 10 Sept 2020.

56. Shajarizadeh A, Hollis A. Delays in the submission of new drugs in Canada. CMAJ. 2015;187(1): E47-51.

57. Morrell L, Wordsworth S, Fu H, Rees S, Barker R. Cancer drug funding decisions in Scotland: impact of new end-of-life, orphan and ultra-orphan processes. BMC Health Serv Res. 2017;17(1):613.

58. Acri KML. Implications of the proposed changes to Canada's pharmaceutical pricing regulations (prerelease chapter). Fraser Institute. 2018. https:// www.fraserinstitute.org/sites/default/files/ implications-of-changes-to-pharmaceuticalpricing-regulations.pdf. Accessed 8 Oct 2020.

59. Martell A. Exclusive: Canadian regulator considers changes to new drug pricing plan. 2020. Reuters. https://www.reuters.com/article/us-canadapharmaceuticals-exclusive/exclusive-canadianregulator-considers-changes-to-new-drug-pricingplan-idUSKBN20E2LI. Accessed 8 Oct 2020.

60. Amgen Canada. Amgen Canada's submission to Health Canada Consultations on the proposed amendments to the patented medicines regulations. 2017. https://www.pdci.ca/wp-content/uploads/ 2017/09/Amgen.pdf. Accessed 12 Aug 2021.

61. PDCI Market Access. Proposed amendments to the patented medicines regulations: a critical appraisal of the cost-benefit analysis. 2018. https://www. pdci.ca/wp-content/uploads/2018/01/20180129_ PDCI-Critical-Assessment-PM-Regs-Amendments_ Report-Final.pdf. Accessed 12 Aug 2021.

62. Canadian Cancer Society. Lung cancer statistics. https://www.cancer.ca/en/cancer-information/ cancer-type/lung/statistics/?region=pe. Accessed 12 Aug 2021. 
63. Tan-Torres Edejer $\mathrm{T}$, Baltussen R, Adam $\mathrm{T}$, et al editors. Making choices in health: WHO guide to cost-effectiveness analysis. Geneva: World Health Organization; 2003.

64. Statistics Canada. Annual demographic estimates: Canada, provinces and territories 2020. 2020. https://www150.statcan.gc.ca/n1/en/pub/91-215x/91-215-x2020001-eng.pdf?st=q-rlkltG. Accessed 12 Aug 2021.
65. Aguilar EJ, Ricciuti B, Gainor JF, et al. Outcomes to first-line pembrolizumab in patients with nonsmall-cell lung cancer and very high PD-L1 expression. Ann Oncol. 2019;30(10):1653-9.

66. Arbour KC, Riely GJ. Systemic therapy for locally advanced and metastatic non-small cell lung cancer: a review. JAMA. 2019;322(8):764-74. 